\title{
“O REINO DE DWORKIN ESTÁ DENTRO DE VÓS”? \\ REFLEXÕES SOBRE O INCIDENTE DE RESOLUÇÃO DE \\ DEMANDAS REPETITIVAS E A POSITIVAÇÃO DA \\ COERÊNCIA E DA INTEGRIDADE NO DIREITO BRASILEIRO
}

\author{
"IS THE KINGDOM OF DWORKIN WITHIN YOU?" REFLECTIONS ON THE \\ INCIDENT OF RESOLUTION OF REPETITIVE DEMANDS AND ON THE
}

NORMATIVE INCLUSION OF COHERENCE AND INTEGRITY UNDER BRAZILIAN

LAW

Recebimento em 05/09/2020

Aceito em 18/10/2020

Cássio Rauédys ${ }^{1}$

\section{RESUMO}

O presente artigo tem o intento de demonstrar que em razão das recentes alterações de inclusão da integridade e da coerência no recente paradigma processual cível brasileiro, tornou-se necessária uma nova abordagem jusfilosófica sobre Direito Processual Civil. Buscou-se, então, demonstrar que a teoria dworkiniana, vista como constrangimento epistêmico, pode, mesmo que reinterpretada através da tese da incorporação do positivismo inclusivo pelos contrários ao interpretativismo, guiar com maior clareza os tribunais no novo dever processual de construção e manutenção de uma jurisprudência estável, íntegra e coerente. Para tanto, utilizou-se de ferramentas teóricas e as contribuições jusfilosóficas de Ronald Dworkin bem como do jurista brasileiro Lenio Streck e, aplicou esta análise a um instituto recém-criado exemplificativo, qual seja o incidente de resolução de demandas repetitivas, para aplicação das teses levantadas. Por fim, concluiu que as noções desenvolvidas pelo interpretativismo, ainda que lidas conforme os pensadores positivistas inclusivos explicam, reforça os deveres aos juízes trazidos pelo horizonte normativo pautado na democratização do Direito processual brasileiro.

Palavras chaves: Dworkin. Integridade. Coerência. Demandas repetitivas.

\section{ABSTRACT}

This article intends to demonstrate that due to the recent changes promoted by the inclusion of integrity and consistency in the recent Brazilian civil procedural paradigm, a new jusphilosophical approach to Civil Procedural Law has become imperative. It was then sought to demonstrate that the Dworkinian theory, seen as an epistemic constraint, even if reinterpreted

\footnotetext{
${ }^{1}$ Mestrando em Direito pela Universidade Federal da Bahia, pós-graduado em Filosofia e Teoria do Direito pela PUC -MG e membro do grupo de pesquisa "Problemas de interpretação jurídica e séries de TV" da Universidade Federal da Bahia.
} 
through the thesis of the incorporation of inclusive positivism and not of a mere interpretativism, can provide the courts with more clarity in regard of this new procedural duty of construction and maintenance of a stable, irreproachable and coherent jurisprudence. In order to do so, this work resorted to the theoretical tools and jusphilosophical contributions from both Ronald Dworkin and the Brazilian jurist Lenio Streck, which were then practically analyzed in connection with the incident of resolution of repetitive demands, an institute created recently. Finally, it was concluded that the notions developed by interpretativism, even if interpreted in accordance with the perception of the positivists, reinforce the duties of the judges that derive from a normative system that is based on the democratization of Brazilian procedural law.

Keywords: Dworkin. Integrity. Coherence. Repetitive demands.

\section{INTRODUÇÃO}

Este trabalho busca traçar um paralelo entre a jusfilosofia interpretativista dworkiniana e as recentes alterações da processualística cível nacional, de modo a permitir a ampliação do entendimento dessa corrente fundamental do pensamento jurídico e sua influência na teoriazação do modelo decisório do Brasil.

O cumprimento do intento ora assumido foi desenvolvido mediante a adoção como metodologia de revisão da literatura pertinente, bem como a análise de um caso de técnica jurídica prevista na legislação e que será utilizado como paradigma. O referencial teórico incluirá a contribuição teórica do professor estadunidense de direito, Ronald Dworkin, pelo menos no que tange a suas ideias de integridade, através das quais estabelece as premissas para a compreensão do Direito a partir de uma lente interpretativista.

Este artigo possui como objetivo geral demonstrar que, através de um estudo de caso, em face dos conceitos utilizados nas codificações, os juristas conseguiriam extrair um melhor entendimento do propósito da mudança legislativa por meio de premissas filosóficos necessárias e fundamentais.

Diante do afirmado, pode-se apresentar a seguinte hipótese: há uma lacuna teórica que requer o aprofundamento nos pressupostos filosóficos e interpretativos dworkinianos, mesmo aos positivistas, para a compreensão de características da abordagem jurídica que inspirou o Código de Processo Civil brasileiro, diante das inclusões dos deveres de coerência e integridade esculpidas no artigo 926 da nova lei. 
De forma exemplificada será analisado a tecnologia de uniformização de jurisprudência criada no artigo 976 desta nova legislação, qual seja, o instituto incidente de resolução de demandas repetitivas à luz da hipótese levantada.

Esta pesquisa é estruturada em cinco seções, dentre as quais: a primeira corresponde a elucidação dos aspectos fundamentais no pensamento jurídico da teoria construtiva interpretativa do professor americano Ronald Dworkin; já a segunda seção é destinada a explicitar a mudança de paradigma jurisprudencial no advento de deveres pela nova legislação processual cível; na terceira seção, logo em seguida, é trabalhada a expectativa de um potencial de constrangimento epistêmico do interpretativismo através da leitura de Lenio Streck aplicado ao direito brasileiro; na quarta seção, por sua vez aponta-se que a influência da filosofia dworkiniana pode ser aproveitada aos juristas positivistas inclusivos através da ideia de incorporação de uma teoria jurídica moral, presentes nos conceitos de coerência e integridade, ao direito positivo; na quinta seção, há uma análise exemplificativa das ideias levantadas ao longo da pesquisa de modo a verificar a compatibilidade destas com o aparato processual do incidente de resolução de demandas repetitivas criado no Código de Processo Civil, símbolo da mudança paradigmática de perspectiva.

Então, já em fase de conclusão, ficou demonstrado que as conceituações e os deveres da atividade jurisprudencial de coerência e integridade produzem uma espécie de incontornabilidade da Filosofia do Direito não apenas para a compreensão, mas também para a adequada operacionalização das mudanças legislativas realizadas e da técnica processual de uniformização desenvolvida porque suas as operacionalizações poderão ser mais bem apreendidas e empreendidas se houver investigação e interpretação constante, à luz do paradigma filosófico e das bases teóricas envolvidas na gênese do Código de Processo Civil de 2015.

\section{AS CONTRIBUIÇÕES JUSFILOSÓFICAS DE RONALD DWORKIN}

Na tradição anglo-americana Ronald Dworkin inicia sua contribuição à Teoria do Direito como um crítico do positivismo jurídico nas teses fundamentais deste pensamento, quais sejam: a de que o direito possui fontes sociais que identificam sua existência e validez; de que dada a necessidade de cotejo entre tais marcos e as situações individuais, os juízes são dotados de graus de discricionariedade; e que existe uma separação entre o direito e a moral, os quais, no máximo, só podem estar associados contingencialmente. 
Para o autor, na teoria positivista há a descrição do direito como um fato, de maneira que a natureza das obrigações "pré-jurídicas", em termos positivistas como aquelas normas que não são emanadas pelas fontes reconhecidas, é um dado que deve ser descrito pelo cientista jurídico sem que valorações, sobretudo de natureza moral, interfiram no conceito que se busca extrair da prática social. Todavia, essa concepção é carente de uma explicação a respeito da legitimação que promove ao enunciar proposições jurídicas, haja vista que ao se afirmar como "direito" algo a ser obedecido, automaticamente elabora-se um elemento de caráter justificador da coerção perpetrada pelo Estado.

Em outras palavras, defende uma ideia de que há associação direta entre o Direito e a justificação da coerção oficial, de modo que uma conceituação do Direito deve, necessariamente, justificar essa conceituação porque diante do "marcador" conceitual "direito", em razão de haver inequivocamente uma pretensão de legitimidade em face de atos coercitivos não-oficiais ou não considerados jurídicos.

Evidenciando, portanto, uma impossibilidade do intérprete de, no mundo da linguagem, o qual condiciona e limita a compreensão, arrogar-se uma posição externa despida de preconceitos, conforme constatações realizadas por Gadamer (MIGUEL, 2012, p. 254).

Desse modo, as teorias do direito que consideram o direito como um fato bruto, como o positivismo, impedem o entendimento dos conflitos interpretativos que estão pautados não na questão semântica mas na própria concepção prévia que se tem da prática social. Logo, a abertura a este nível de compreensão das divergências ${ }^{2}$ revelam em relação ao fenômeno jurídico sua natureza essencialmente argumentativa de disputa que envolverá fatalmente a impressão de propósitos diferenciados, os quais, por sua vez, afetam a interpretação que se terá dele.

O autor americano ataca frontalmente a tese da separação entre direito e moral e a perspectiva pretensa e exclusivamente descritiva do positivismo de Herbert Hart, considerada por Dworkin, a versão mais refinada da referida corrente.

Para ele, a interpretação teria etapas, desconsideradas pelos positivistas, dentre as quais a pré-interpretativa, a interpretativa e a pós interpretativa.

\footnotetext{
2 "A divergência empírica sobre o direito quase nada tem de misteriosa. As pessoas podem divergir a propósito de quais palavras estão nos códigos da mesma maneira que divergem sobre quaisquer outras questões de fato. Mas a divergência teórica no direito, a divergência quanto aos fundamentos do direito, é mais problemática. [...] Advogados e juízes têm, de fato, divergências teóricas. Divergem, por exemplo, sobre o que o direito re almente é, sobre a questão da segregação racial ou dos acidentes de trabalho, mesmo quando estão de acordo sobre as leis que foram aplicadas, e sobre o que as autoridades públicas disseram e pensaram no passado." (DWORKIN, 2003, p. 8)
} 
Durante a etapa pré-interpretativa se identifica e qualifica o objeto de interpretação recorrendo aos materiais que integram substancialmente a prática. Todavia, o caráter de prévio desse momento é acompanhada por uma advertência do filósofo de que já há aqui um nível de interpretação para identificar esse material consensual de que se possa partir.

Já na etapa interpretativa ocorre a busca do intérprete pela justificação geral do propósito perseguido pela prática que está envolvido ou nas palavras de Dworkin (2003, p. 81):

\begin{abstract}
A justificativa não precisa ajustar-se a todos os aspectos ou características da prática estabelecida, mas deve ajustar-se o suficiente para que o intérprete possa ver-se como alguém que interpreta essa prática, não como alguém que inventa uma nova prática.
\end{abstract}

Por fim, na etapa pós interpretativa ocorre um ajuste $(f i t)$ entre o material identificado na primeira etapa e sua justificativa para estruturar a aplicação do Direito na sua melhor luz dentre as possibilidades que os elementos permitem, de sorte que há uma interconexão entre da melhor justificação moral com o apontamento da melhor interpretação jurídica, envolvendo nesse interim, inclusive, a introdução, modificação ou suplantação de elementos presentes no material identificado na primeira etapa orientando ao propósito moral que subjaz à prática.

Em relação a regra de reconhecimento formulada por Hart, que é uma norma social constituída das práticas e comportamentos compartilhados dos membros de uma sociedade, tais como juízes e funcionários estatais, segundo a crítica dworkiniana, diante da divergência sobre a regra que forneceria os critérios de validade jurídica tal precrição deixaria de funcionar (ORUNESU, p. 234).

O pensador americano também lida com a lacuna da discricionariedade judicial gerada pela textura aberta hartiana em casos considerados não-claros (STRUCHINER, 2002, p. 6), ao entender que a despeito de em determinadas situações não existirem regras claras, não é incomum aos juízes apelarem para normas não conclusivas e não emanadas diretamente das fontes reconhecidas de direito para tomarem suas decisões.

Dworkin (1999, p. 271), em relação a esses casos obscuros difícieis e também aos considerados fáceis, entende que o Poder Judiciário deve identificar os direitos e deveres dos casos apresentados anuindo com o pressuposto de que foram criados por um autor dotado de uma "única voz" e caracterizado como uma "comunidade personificada", de forma que seria inconcebível a defesa de teses que não implicam que é possível encontrar uma resposta correta aos casos jurídicos apresentados aos julgadores por meio de uma concepção da integridade. 
Essa atividade decisória do direito como integridade exige uma interpretação incessante e itinerante na qual, até mesmo a divergência (DWORKIN, 1999, p. 287), por força do comprometimento com a integridade, confirma e realiza o propósito desta, qual seja, "de ser uma comunidade de princípios" estruturados coerentemente (DWORKIN, 1999, p. 291) e por isso apto a encontrar as respostas corretas à luz do Direito.

Por isso que a interpretação jurídica seria construtiva, exaxtamente porque é uma atividade que está numa tradição, portanto atada a horizontes pré-compreensivos, porém aberta à superação a à modificação em face da consciência crítica desse contexto.

Nesta senda, é indispensável para entendermos sua proposta, tratar da diferença que Dworkin (1999, p. 265) faz em $O$ império do direito entre a integridade e a coerência.

Enquanto a segunda é concebida como uma unidade dos posicionamentos jurídicos dos órgãos julgadores que devem ser aplicados isonomicamente, a primeira supõe a adesão a uma concepção de direito que se expressa dinamicamente de investigação e de interpretação por força do caráter hermenêutico das normas, de maneira a não possuir uma ligação necessária e exclusiva com o reforço das decisões anteriores sob receio de não incorrer em "incoerência".

Dworkin (1999, p. 213) separa a integridade política em dois princípios, um com vistas a orientar ao legislador para manter o conjunto das leis produzidas com coerência moral e outro de caráter jurisdicional que exige a interpretação judicial coerente.

De maneira resumida, pode-se compreender que a integridade legislativa para o citado pensador diz respeito às atividades dos legisladores ao criar ou modificar os padrões normativos públicos e a integridade adjudicativa ou judicial como fruto da virtude política dos juízes consistente em expressar e respeitar padrões principiológicos inexplícitos coerentes (POGREBINSCHI, 2012, p. 1), os quais permitem chegar a um resultado específico correto.

A comunidade personificada orientada para a integridade seria uma comunidade organizada por princípios e na qual os membros sejam dotados de igual respeito e reconhecimento em que decisões são justificadas por princípios aceitos por todos de modo a se contrapor a concepções de comunidade cuja constituição está vinculada a interesses de natureza pragmática ou a mera subordinação ao sistema de regras (GÜNTER, 2004, p. 409).

Esta integridade na deliberação judicial ou adjudicação (DWORKIN, 1999, p. 261) significa, em outras palavras, que os julgadores devem interpretar o ordenamento jurídico de maneira que neste esteja subentendido um "conjunto coerente de princípios" e para atenderem a este "subentendimento" promoverão o expediente interpretativo orientado por este ideal político de dar um sentido holístico à história da prática jurídica, o qual a revelará na sua "melhor luz" bem como implicará no "interesse de cada um por tudo que é suficientemente especial, pessoal, 
abrangente e igualitário para fundamentar as obrigações comunitárias segundo as normas de obrigação comunitária" (DWORKIN, 1999, p. 260). O Direito como integridade oferecerá, nestes termos, uma interpretação construtiva melhor em relação à prática jurídica.

A tese do "romance em cadeia" capta metafórica e epistemologicamente a proposta dworkiniana na qual,

Cada um deve escrever seu capítulo de modo a criar da melhor maneira possível o romance em elaboração, e a complexidade dessa tarefa reproduz a complexidade de decidir um caso difícil de direito como integridade. [...] Cada romancista pretende criar um só romance a partir do material que recebeu, daquilo que ele próprio the acrescentou e (até onde lhe seja possível controlar esse aspecto do projeto) daquilo que seus sucessores vão querer ou ser capazes de acrescentar. Deve tentar criar o melhor romance possível como se fosse obra de um único autor, e não, como na verdade é o caso, como produto de muitas mãos diferentes. (DWORKIN, 1999, p. 276)

Assim, a proteção à integridade do direito se dá por um mecanismo que não apenas pretende apresentar uma resposta coerente com o ordenamento jurídico ou com o catálogo jurisprudencial existente, mas que constrói interpretativamente a resposta que no momento demonstre a melhor (DWORKIN, 1999, p. 287), mesmo que juízes engajados nessa tarefa cheguem a respostas distintas.

O que, para Dworkin (2012, p. 161-163), gera um ceticismo a respeito da interpretação certa o qual, por sua vez, acarreta uma reticência em buscar a verdade das interpretações e essa busca que se faz é o âmago da interpretação, porque apenas com a ideia de admitir a existência de uma verdade, ou uma resposta correta no caso do Direito, é possível prosseguir interpretativamente já que o sucesso nessa empreitada os objetivos intrínsecos e justificativos ${ }^{3}$ se unem, de modo que os pressupostos a respeito desses objetivos e a valoração deles para o sujeito, mesmo que sem reconhecimento consciente ou uma perceptível articulação, elaboram os critérios de aceitabilidade das afirmações com pretensões interpretativas.

É daí que nasce uma das objeções mais profundas à tese positivista, a de que a epistemologia dessa teoria altera a forma como o intérprete do Direito irá enunciar as

\footnotetext{
${ }^{3}$ Em qualquer investigação há dois tipos de objetivos, um é intrínseco, isto é, achar a verdade sobre algo e o outro é justificativo, ou seja, os intentos ou as intenções que dão justificativa à tentativa de encontrar a referida verdade. Nem sempre esses intentos justificatórios são de natureza prática como a medicina está para a cura e prevenção de doenças porque as vezes se considera algo com importância crucial para o conhecimento humano, como a cosmologia que pode não agregar imediatamente uma justificativa próxima à prática. Ademais, diferentemente dos objetivos intrínsecos de alguma ciência que são submetidos a algum teste de aproximação ou distanciamento da verdade, os objetivos justificativos não o são porque constituem razões que movem o querer em direção ao sucesso de achar o verdadeiro. Quando um cosmonauta estuda seu campo com o objetivo justificativo de ser encantado pelo universo, este encantamento não está submetido a um teste a respeito de sua verdade (DWORKIN, 2012, p. 160-161).
} 
proposições jurídicas com pretensões de validade. Ao apontar apenas o objetivo intrínseco, mantém submersa um objetivo justificatório que redefine o primeiro sem que os positivistas, pelo menos os não normativos, percebam e/ou a exponham.

Após esse breve histórico dos aspectos mais relevantes do pensamento dworkiniano se fará o cotejo entre tamanha contribuição teórica e os novos desenhos criados na jurisprudência brasileira por força do novo Código de Processo Civil.

\section{O NOVO DEVER DE MANTER A JURISPRUDÊNCIA ESTÁVEL, ÍNTEGRA E COERENTE}

Ao mesmo tempo dos desdobramentos apontados na Filosofia do Direito, ocorria o desenvolvimento do neoconstitucionalismo no Brasil, o qual colocou em evidência Dworkin pela centralidade dos princípios morais e políticos para interpretar do direito (MACEDO JR, 2013, p. 41), os quais se ajustaram bem ao clima intelectual que delineou o caráter da Constituição de 1988, bem como fortaleceu a necessidade teórica de justificação do poder, haja vista as perdas democráticas e os traumas políticos em razão do período do regime militar.

Em tal contexto e diante da imensidão de demandas, do crescente acesso ao Poder Judiciário e por força de princípios constitucionais, como da igualdade, a nova codificação processual cível brasileira visou proteger as expectativas democráticas e igualitárias dos jurisdicionados em face da potencialidade e da realidade de decisões muito distintas entre si emanadas pelo Estado.

Os juristas, reféns de uma espécie de "positivismo intuitivo" que orienta em direção a uma via interpretativa marcada pelo prestígio ao significado dos textos das normas, provavelmente provocado pela experiência universitária pautada em constante consulta a materiais sem preparação por parte dos professores a respeito de teorias e métodos interpretativos (DIMOULIS, 2011, p. 217), começaram a perceber que o voluntarismo judicial, alimentado pelo princípio do livre convencimento do juiz (STRECK, 2014), estava permitindo uma discricionariedade, no momento da adjudicação, ameaçadora de um sistema de justiça imbuído constitucionalmente de ser democrático.

Essa percepção surgiu e foi se fortalecendo por situações de tensão entre doutrinadores e estudiosos do Direito com julgadores como se ilustrou em certa manifestação do Ministro do Superior Tribunal de Justiça, Humberto Gomes de Barros, quando no julgamento de agravo regimental em ERESP 279.889-AL, que afirmou peremptoriamente, 
Não me importa o que pensam os doutrinadores. Enquanto for ministro do Superior Tribunal de Justiça, assumo a autoridade da minha jurisdição. O pensamento daqueles que não são ministros deste Tribunal importa como orientação. A eles, porém, não me submeto. Interessa conhecer a doutrina de Barbosa Moreira ou Athos Carneiro. Decido, porém, conforme minha consciência. Precisamos estabelecer nossa autonomia intelectual, para que este Tribunal seja respeitado. É preciso consolidar o entendimento de que os Srs. ministros Francisco Peçanha Martins e Humberto Gomes de Barros decidem assim, porque pensam assim. E o STJ decide assim, porque a maioria de seus integrantes pensa como esses ministros. Esse é o pensamento do Superior Tribunal de Justiça e a doutrina que se amolde a ele. É fundamental expressarmos o que somos. Ninguém nos dá lições. Não somos aprendizes de ninguém. [...].

Posturas judicantes como essa começaram a despertar na sociedade, sobretudo naquela parcela em que questões relativas ao aprimoramento e à evolução do Estado Democrático de Direito lhes eram mais sensíveis intelectualmente, a necessidade de adequar o principal código processual do país para as exigências da Constituição Federal de 1988.

O artigo 926 do Código de Processo Civil, que passou então a prever os deveres dos tribunais de uniformizar sua jurisprudência e de mantê-la estável, íntegra e coerente, concede pistas a respeito das próprias premissas filosóficas que animaram a inclusão desses dispositivos legais.

Tratou-se, a bem da verdade, em nível filosófico, de uma forte reação à tese predominante da discricionariedade do positivismo jurídico que dificultava a construção de um modelo decisório pautado pelos valores morais e discursivos esculpidos na própria constituição democrática, através de uma ideia de "livre convencimento" consagradora do subjetivismo dos juízes (STRECK, 2017, p. 258), em detrimento da busca por uma resposta judicial que se apresenta como expressão da melhor interpretação possível e não de um ato de vontade animado por uma disposição totalmente livre, pessoal e animado pelo espírito kelseniano para o qual,

Na medida em que, na aplicação da lei, para além da necessária fixação da moldura dentro da qual se tem de manter o ato a pôr, possa ter ainda lugar uma atividade cognoscitiva do órgão aplicador do Direito, não se tratará de um conhecimento do Direito positivo, mas de outras normas que, aqui, no processo da criação jurídica, podem ter a sua incidência: normas de Moral, normas de Justiça, juízos de valor sociais que costumamos designar por expressões correntes como bem comum, interesse do Estado, progresso, etc. Do ponto de vista do Direito positivo, nada se pode dizer sobre a sua validade e verificabilidade. Deste ponto de vista, todas as determinações desta espécie apenas podem ser caracterizadas negativamente: são determinações que não resultam do próprio Direito positivo. Relativamente a este, a produção do ato jurídico dentro da moldura da norma jurídica aplicada é livre, isto é, realiza-se 
segundo a livre apreciação do órgão chamado a produzir o ato. (KELSEN, 1998, p. 249)

Este tipo de abordagem positivista, pretensamente avalorativa, respalda um descontrole epistêmico da decisão dado que o juiz, ao individualizar a norma à concretude do caso, terá um trunfo teórico que legitima a decisão judicial como objeto exclusivo de seu controle individual, o qual não está, necessariamente, atrelado ao desenvolvimento histórico da tradição jurídicas, aos propósitos morais do próprio Direito do qual se serve a comunidade política e, ainda, a qualquer justificação do decidido em referência ao grau de consonância com todo o ordenamento jurídico e isso termina por se traduzir numa opção de moralidade política, diga-se pouco democrática, disfarçada.

Por essa razão, neste trabalho defende-se que o novo do Código de Processo Civil se constitui filosoficamente como uma reação e uma afirmação de uma abordagem interpretativista dworkiana, seja por declarações expressas realizadas quando do tempo de sua formulação (STRECK, 2014) ou pela própria necessidade de tratar de conceitos como coerência e integridade, ambos extensamente estudados por Ronald Dworkin e evidenciados como democraticamente revigorantes pela doutrina brasileira.

\section{A TEORIA DWORKINIANA COMO CONSTRANGIMENTO EPISTÊMICO AOS JUÍZES NAS DECISÕES JUDICIAIS}

Com a positivação de determinados conceitos, como a integridade e a coerência, que possuem premissas filosóficas bem delineadas atribui-se ao julgador, de forma explícita, o papel de autor de um discurso, no caso jurídico, que tem passado e também avança em direção ao futuro com um propósito de se tornar a "narrativa" a melhor possível de maneira e essa ideia é um forte constrangimento epistêmico.

Em outras palavras, significa o rechaço à "quebra da cadeia discursiva", conforme afirma Streck (2014), a ser perpetrada por um simples ato de vontade do juiz em mudar a orientação jurídica dada às demandas que lhes são apresentadas. Qualquer mudança na "cadeia discursiva" do direito tem que, argumentativamente, justificar-se perante uma história judicial e uma comunidade de princípios pressupostos às próprias regras postas que são descobertos argumento e hermeneuticamente.

Há, então, um dever que implica na mudança de postura jurisdicional teórica, que deixa de ser encarada como um procedimento mental de convencimento pessoal a respeito da devida 
interpretação das normas colocadas, cujo resultado é individualmente construído livre de constrangimentos, para ser compreendida como um procedimento mental de convencimento pessoal condicionado a imperativos hermenêuticos que não permitem contornar o desenvolvimento histórico, tampouco os propósitos justificatórios da própria coerção oficial.

A consequência disso, conforme o jurista brasileiro, é a democratização do direito porque as contraditas à centralidade do subjetivismo passam a integrar de forma fundamental o processo de desenvolvimento e interpretação (STRECK, 2014).

Não haveria espaço, com a incorporação da integridade como paradigma compreensivo do direito, para decisões judiciais que se justifiquem como fruto de uma escolha possível e disponível aos julgadores para pronunciarem-se com suas vozes pessoais simplesmente impregnadas de poder legiferante livre em absoluto no que diz respeito às normas individuais concretas.

Afasta-se definitivamente da postura da judicatura solipsista exemplificada nos seguintes termos "minha convicção aponta para a interpretação X e o poder a mim conferido permite que eu a eleja como a adequada", para uma disposição no seguinte modelo: "em face dos princípios que arquitetam moralmente essa comunidade e que revelam a justificação do direito reconhecido, bem como da história do desenvolvimento jurídico entre nós, a melhor interpretação jurídica será Y".

A esta postura Dworkin dá o nome de integridade (GÜNTER, 2004, p. 407) que combaterá a postura judicial de solipsismo, então explicada como decorrência da ausência de posição filosófica e política sobre o direito pretendida pelos positivistas, também chamada de "ponto arquimediano" por Dworkin é um objetivo inalcançável porque para este autor qualquer proposição jurídica com pretensão de validade guarda em si uma profunda reflexão filosófica e política sobre o propósito do Direito a tal proposição, inclusive, pode estar em desacordo com outras proposições também levantadas pelos demais agentes, de modo que para além dos desacordos empíricos sobre a "aplicação do Direito", as contentas jurídicas em um nível mais elevado de abstração teórica são dotadas de divergências morais significativas.

Em outras palavras, na ausência um local privilegiado "fora de moralidades", toda pretensão analítica já está imersa em pré-compreensões sobre o sentido moral que deve ser dado na atividade interpretativa a ser realizada, inclusive em relação a escolha moral a respeito de um decisionismo descontrolado epistemologicamente como o que era vigente no Brasil.

A concretude que virá de um direito mais abstrato, não decorre dessa maneira simplesmente de uma subsunção aparentemente neutra, mas de uma teoria moral e política (DWORKIN, 2000, p. 531) que irá justificar a concepção da permissividade como concepção 
concreta desse direito de forma subjacente (DWORKIN, 2000, p. 533) e o descontrole democrático acima referido deve deixar de ser encarado como um fato natural, mas como uma opção política e moralmente orientada.

Isso porque, para Dworkin, em face da indeterminação das regras jurídica resta ao intérprete se valer de direitos ou princípios que não estão integralizados a ordem jurídica por meio de uma regra de reconhecimento e dentre estes aponta como essenciais a igual consideração e o igual respeito (GÜNTER, 2004, p. 404 - 405).

Em cada decisão, o juiz concerta uma ligação coerente entre o decidido uma teoria política geral (GÜNTER, 2004, p. 405), uma vez que as regras e os princípios aceitos pela comunidade política devem justificar da melhor forma a formulação jurídica emanada para a sociedade e com eles ser compatível.

Este pequeno esforço narrativo trazido apenas visou demonstrar o ônus argumentativo aumentado e redirecionado que o dworkianismo pretende e acatado pelo legislador nacional em 2015 para que o juiz deixasse de ser um destinatário do convencimento e passasse a se tornar a parte responsável pela justificação da adoção de determinada orientação em articulação com outros elementos distintos da sua própria convicção.

\section{A "INCORPORAÇÃO" DE DWORKIN AO DIREITO POSITIVO: O POSITIVISMO INCLUSIVO COMO UMA FRONTEIRA CONVENIENTE E UM APOIO SUBSIDIÁRIO}

O curioso do desenvolvimento da história jurídica até agora estudado, é que mesmo para um jurista positivista no Brasil, por mais incongruente que isso possa soar, levando-se em consideração as divergências profundas, pode haver um dever de proceder metodologicamente como um dworkiniano, visto que a jurisprudência íntegra demanda uma justificação da escolha por uma interpretação da norma articulada, também por isso condicionada, com e à determinação em se proceder ao ato interpretativo anuindo com a ideia de que o Estado deve se pronunciar como detentor de uma única voz e com o propósito de que o direito aplicado seja fruto de uma interpretação coerente com o conjunto de princípios que formatam a comunidade.

Isso caso se convençam de que estão se defrontam com uma tentativa de incorporação de uma teoria jurídica pelo legislador ao corpo positivo do direito processual cível, de maneira a entrelaçar a Filosofia do Direito de Dworkin ao raciocínio positivista nesse campo do conhecimento. 
Sendo possível, a despeito de qualquer doutrina da discricionariedade anteriormente respaldada, positivamente apontar a necessidade expressa, mas não surpreendente, de enfrentamento da proposta dworkiniana, por força da inserção do "dworkianismo" no artigo 976 do Código de Processo Cível, o qual tem sua paternidade intelectual, ainda nos debates acadêmicos e discussões parlamentares, atribuída ao jurista brasileiro Lênio Streck $(2015$, p. 41), o qual apoiou que o dispositivo acrescido poderá proporcionar doutrinariamente um "controle epistêmico" (STRECK, 2013) face à ideia discricionariedade judicial propalada pelos modelos tradicionais de regras que adentrou as mentes dos juristas (DWORKIN, 2002, p. 49).

O que poderia acarretar concomitantemente, embora não seja o escopo do presente trabalho, uma aprazível e conveniente aproximação com a tendência de orientação jusfilosófica ao positivismo jurídico includente ${ }^{4}$, para o caso de a virtude política dworkiniana vier a ser considerada como critério de ordem moral inserido nos "fundamentos posibles para estabelecer la existência e el contenido de las leys positivas válidas, es decir, de las leyes sanciconadas o creadas por seres humanos por médio de legislaturas, tribunales o la práctica consuetudinária' (WALUCHOW, 2007, p. 17).

Esta escola defende que, se o direito "é" aquilo que advém da sua interpretação, não necessariamente identificado com o direito "como deve ser" (MARANHÃO, 2012, p. 64), permitiria aos positivistas a manterem algumas de suas premissas.

A partir desse tipo de análise, este projeto de incorporação que o direito brasileiro tenta realizar, pode também servir para trazer a determinados positivistas a ideia de que a virtude política da integridade promove maior autoridade moral e justificatória da coerção jurídica, afastando vícios de parcialidade, fraudes e atividades corruptivas (DWORKIN, 1999, p. 228).

O "impasse proveitoso" do positivismo jurídico brasileiro com a adesão a esta concepção implicaria no fato de que promover um dever ao jurista contrário à perspectiva interpretativista o acatamento da opção legislativa por uma metodologia dworkiniana e, tudo isto, por força de sua própria convicção positivista.

É preciso ressaltar que, entre a abordagem dworkiniana (1999, p. 263), ora defendida em caráter principal, que estabelece uma espécie de cenário moralmente justificado e justificatório, no qual o juiz que abraça a integridade no raciocínio a respeito do Direito ao tentar estabelecer

\footnotetext{
${ }^{4}$ Esta orientação, que é objeto de cogitação de Philip Soper (1977, p. 514), positivista hartiano da vertente includente, para o qual "moral standards become relevant to legal decisions in both cases only because they are contingently, not necessarily, made relevant by social rules. Content is crucial in deciding which standards to use, but only because pedigree makes it so. The fact that one cannot provide a proof procedure either for checking the accuracy of decisions employing such legally adopted moral standards or for demonstrating which such standards are the correct ones, does not affect the core claim that legal and moral standards are conceptually distinct."
} 
genuína e univocamente os direitos devidos às partes na contenda judicial, e a esposada proposta subsidiária, aproximativa e pragmática de interpretar a positivação do dever dos tribunais produzirem jurisprudência íntegra e coerente como incorporação da integridade é um rompimento teórico e filosófico imenso.

Essa alternativa sucedânea relembra em muito Herbert Hart (p. 331), que em seu post scriptum do Conceito do Direito conjecturava sobre a hipótese de que o "critério interpretativo holístico", comprendenda-se dworkiniano, poder ser respaldado por meio de uma regra de reconhecimento como critério para identificação de princípios jurídicos.

Todavia, como se sabe, Dworkin $(1999$, p. 157 - 158) foi um contundente crítico dessa modalidade de positivismo, sobremaneira na obra $O$ império do direito, quando aponta suas diferenças em relação ao que chega a chamar de "convencionalismo moderado".

Enquanto para o positivismo jurídico inclusivo, ou positivismo moderado, a relação entre direito e moral é contingencial, na sua teoria do direito como integridade "o argumento jurídico é completamente moral, ao ponto de que não há como identificar o direito sem que se façam, também, alegações morais e éticas" (STRECK, 2018, p. 69).

\section{A COERÊNCIA E A INTEGRIDADE EM AÇÃO: ANÁLISE DO INCIDENTE DE RESOLUÇÃO DE DEMANDAS REPETITIVAS}

Ao mesmo passo que as mudanças legislativas apontadas no presente estudo atingem fundamentos teóricos é salutar para que esta pesquisa ganhe contornos fáticos a análise de constructos e tecnologias processuais que pretendem concretizar, ou no mínimo não obstar, os ideais jurídicos desenvolvidos na pesquisa.

Diante das situações de litigiosidade em larga escala e da imprescindibilidade de preservação da isonomia, inovações foram demandadas por razões de insuficiência do modelo anterior baseado na dicotomia entre as tutelas individuais e coletivas, sem uma interlocução que promovesse a garantia do tratamento isonômico diante de pleitos individuais homogêneos (WAMBIER; DIDIER JR; TALAMINI; DANTAS, 2015, p. 2178) e vitimado pelo solipsismo.

Neste contexto de mudança de orientação filosófica e atendendo a anseios, aparece o incidente de resolução de demandas repetitivas como uma técnica jurídica para lidar, em harmonia ao novo paradigma, com a litigância em massa de modo a reconhecer que,

É imprescindível, em um Estado Constitucional, zelar pela igualdade de tratamento em face das decisões judiciais. Nada nega tanto a igualdade quanto 
dar, a quem já teve o seu direito violado ou sofre iminente ameaça de tê-lo, uma decisão desconforme com o padrão de racionalidade já definido pelo Judiciário em casos iguais ou similares. (MARINONI, 2013, p. 164)

O incidente criado $^{5}$ no direito positivo brasileiro ocorrerá em face de uma efetiva repetição de processos originado por um dissenso interpretativo, não havendo espaço para instauração diante apenas de um dissenso potencial sob risco de se implantar a padronização preventiva da jurisprudência, o que é proibido (NUNES, 2015).

Conforme o artigo 976, incisos I e II, do Código de Processo Cível, poderá ser instaurado o incidente quando houver repetição de processos a respeito de controvérsias sobre a mesma questão unicamente de direito e que ameace ofender a isonomia e a segurança jurídica.

Para se ter proporção da importância dessa ferramenta processual, a matéria a ser uniformizada produz tamanho risco de prejuízo à isonomia e à segurança jurídica em seu processamento por meio de entendimentos dispersos, que o legislador chegou ao ponto de ter manter o julgamento, mesmo diante da desistência ou abandono das partes em lide como fixa os parágrafos $2^{\circ}$ e $3^{\circ}$ do artigo 976 da supracitada codificação.

Dito isso, a princípio, é possível afirmar que a noção de coerência, a partir da concepção de Dworkin, é compatível com o incidente de resolução de demandas repetitivas previsto no código aprovado porque este se caracterizará numa tentativa de promoção da igualdade de tratamento por parte do Poder Judiciário aos jurisdicionados, visto que o intento, além da solução concreta das lides, é a uniformização do entendimento judicial de modo a consagrar a isonomia.

Com relação a ideia de integridade, que no paradigma dworkiniano em sua forma judicial exige que a interpretação da lei seja coerente com o conjunto das normas da comunidade, a compatibilidade fica mais bem percebida no indicado instituto, quando se leva em consideração que a uniformização de entendimento implica o aperfeiçoamento da capacidade do Estado se pronunciar numa só voz a respeito de uma questão jurídica recorrente somada à possibilidade de revisão de tese, já que esta tem previsão no artigo 986 do supracitado Código.

Afinal, como tal ideia traduz-se numa concepção interpretativista do direito em coerência com sua história, seu desenvolvimento e sua totalidade, haverá sempre a chance de os julgadores encontrarem interpretações melhores e respostas corretas distintas das consagradas no passado, haja vista que, em Dworkin, o convencionalismo não tem lugar na abordagem do direito como integridade.

\footnotetext{
${ }^{5}$ Como se pode extrair da própria exposição de motivos, na qual a Comissão reformadora atribui inspiração direta no sistema de casos massificados da Alemanha, apesar de ter, conforme afirma Oliveira (2016, p. 65), herdado poucos elementos.
} 
Essa situação de "tensão entre integridade e coerência" (MIGUEL, 2012, p. 248) se estabelece quando o intérprete lida com a tradição a qual pertence e a qual está vinculado ao mesmo tempo em que se abre a superação desse condicionantes que atuam inclusivo em nível pré-compreensivo.

Assim, a estrutura de princípios implícitas que tentará trazer à decisão prolatada sua melhor justificação moral comunitária pode ter com base em algum aspecto não enfrentado pela tese outrora vencedora, para que não se consagrar, em nome da coerência, a manutenção de erros de julgamento que não revelaram o direito na sua melhor luz moral.

Além de que, mesmo com a própria aplicação futura do precedente a um novo caso, se terá de forma inescapável uma nova interpretação por parte dos juízes (NETO; ZANETI, 2016, p. 17).

Para tanto, o conceito de integridade terá, inclusive, mais limites que o de coerência porque enquanto esta volta-se para o passado considerando-o como um marcador de "limites" verticais interpretativos, já aquela propõe que se volte para a jurisprudência formada preteritamente ao ato interpretativo atual, como maneira de reconstrução do melhor sentido da história da prática jurídica (DWORKIN, 1999, p. 274), mantendo-se focada nas determinações do presente e também no potencial criativo revelador de uma interpretação melhor, sendo possível, portanto, modificar uma justificação jurídica anterior, por exemplo, quando não se considerou determinados elementos ou aspectos (GÜNTER, 2004, p. 405).

A metáfora da "teia inconsútil" visa demonstrar que o prosseguimento histórico do direito deve manter sua integridade no sentido de que uma continuidade coerente, mas não meramente repetitiva (DWORKIN, 2002, p. 177), deve ocorrer tal como um "romance em cadeia" no qual as determinações dos capítulos passados ou a "força gravitacional das decisões anteriores" são limitadas pelo propósito da interpretação da obra do qual o capítulo a ser escrito será resultado e justificação concomitantemente, do mesmo modo que os princípios que justificam as decisões operam sobre a interpretação nova (DWORKIN, 2002, p. 117).

Essa relação imbrincada e concomitante de adequação e justificação é alegoricamente desempenhada pelo juiz Hércules ${ }^{6}$ que assume um compromisso com a tese do direito como integridade.

Logo, os jurisdicionados não ficarão apenas cientes de quais normas e quais decisões anteriores os governam, mas saberão que diante de novos ou dos mesmos conflitos,

\footnotetext{
${ }^{6}$ Guest (1997, p. 39) aponta que o juiz Hércules é um ideal, tal como a idealização econômica de mercado perfeito de modo que se pode avaliar e criticar o real pelo ideal sem que para isso seja necessário afirmar que o ideal realmente exista.
} 
redimensionados ou não, um refinamento na interpretação dos decisores poderão captar aspectos novos que decorram dos princípios pressupostos das fixações de sentido anteriores, os quais estão em transformação orgânica (DWORKIN, 1999, 229).

Em suma, este espírito do novo regime de precedentes, afirma Lenio Streck (2014), poderá ser verdadeiramente superar uma padronização danosa dos posicionamento das cortes, visto que a construção do padrão possuirá a exigência de coerência e de integridade, as quais serão verdadeiras chaves de leitura que atuarão para impedir a cristalização decorrente do mero apego às decisões passadas pelo simples fato de serem pretéritas e não pelo seu valor argumentativo dentro do desenvolvimento do contexto normativo da comunidade de princípios.

Assim, o entendimento desse instrumental dependerá, conforme se defende neste artigo, de um diálogo sério com a Filosofia do Direito dworkiniana e não apenas mera especulação abraçando o interpretativismo como melhor lente teórica, ou no mínimo, para os insistentes na teoria positivista, da percepção tentativa de incorporação ao direito de virtudes da integridade e da coerência juntas à ideia de que os juízes devem decidir da melhor maneira possível, já que o direito deverá objetivar ser o mais coerente com o sistema ao qual pertencem (íntegra) e se concretizar numa aplicação igual aos casos iguais (coerente).

\section{CONSIDERAÇÕES FINAIS}

A abordagem do Direito como integridade desenvolvida ao longo deste trabalho é marcada pela expressão verbal "exigir", que marca seu caráter eminentemente normativo, no sentido de que é requerido um comportamento concreto dos juízes em relação um comportamento paradigmático e deste caráter pertence sua figuração do tipo ideal de juiz Hércules, que sempre se pergunta de sua interpretação em determinada demanda poderia "fazer parte de uma teoria coerente que justificasse" a "rede de estruturas e decisões políticas de sua comunidade" tomadas como um todo (DWORKIN, 1999, p. 294).

Chegou-se a conclusão que as atividades investigativas, imaginativas e integrativas dos juízes desenhadas pelo Código de Processo Civil de 2015 será marcada por descobertas e desvelamentos que poderão apontar para uma interpretação inovadora, mas que atende melhor aos propósitos de justificação moral do direito porque dotada de maior compatibilidade com os princípios fundamentais do sistema jurídico.

O que leva a crer que, uma vez atendidas as premissas teóricas, a figura paradigmática e ilustrativa da pesquisa, qual seja, o incidente de resolução de demandas repetitivas, pode 
desempenhar no direito brasileiro um papel muito maior e mais relevante que a mera criação de padrões de decisão quanto a dissensos "de direito", nos termos usados pelo legislador, constituindo-se, dado que amalgamados pelos objetivos de coerência e integridade, numa tecnologia processual a serviço da realização dos fins de democratização do processo e de compromisso substantivo da teoria jurídica com o Estado Democrático de Direito.

Deve-se, por fim, lembrar que a perspectiva do autor norte-americano que se objetivou demonstrar é a de intérprete e ainda que, exteriormente, não se verifique uma coação incontroversa ao seu aspecto normativo, o fato dela existir do ponto de vista de quem realiza a interpretação já é suficiente para justificar sua abordagem (DWORKIN, 1999, p. 284).

Porém, como é sabido, há a possibilidade de que a ideia do mero "livre convencimento do juiz" como fonte da interpretação das normas remanesça no "espírito" dos julgadores pátrios, a despeito do distanciamento realizado pela nova codificação, porque a positivação de elementos de uma teoria interpretativista pertencente a uma tradição, que não a brasileira, pode acarretar um estranhamento ou uma adaptação deturpada.

Em função disso, não seria descabido um comedimento ao otimismo, o que é também esposado por Streck (2015, p. 49 - 50), o qual é assertivo ao alertar que, sem entender o novo modelo adotado na sistemática processualística cível, haverá um risco da transformação paradigmática da construção da decisão judicial nesse âmbito se revelar uma nova roupagem aos velhos raciocínios.

Por isso, o estudo de Ronald Dworkin, conforme buscou-se demonstrar ao longo desta produção, se já era indispensável aos juristas contemporâneos brasileiros, torna-se incontornável mesmo em contextos pretensamente "dogmáticos" e inclusive dos adeptos, declarados ou não, de determinadas teses comumente atreladas aos positivismos.

\section{REFERÊNCIAS}

BRASIL. Lei $\mathbf{n}^{\mathbf{0}} \mathbf{1 3 . 1 0 5}$ de 16 de março de 2015. Disponível em:

http://www.planalto.gov.br/ccivil_03/_ato2015-2018/2015/lei/113105.htm. Acesso em: 11 jun. 2020 .

DWORKIN, Ronald. Justiça para ouriços. Tradução: Pedro Elói Duarte. Coimbra: Editora Almedina, 2012.

DWORKIN, Ronald. Levando os direitos a sério. Tradução e notas: Nelson Boeira. São Paulo: Martins Fontes, 2002. 
DWORKIN, Ronald. O império do direito. Tradução: Jefferson Luiz Camargo. São Paulo: Martins Fontes, 1999.

DWORKIN, Ronald. Uma questão de princípio. Tradução: Luiz Carlos Borges. São Paulo: Martins Fontes, 2000.

GUEST, Stephen. Ronald Dworkin. 2. ed. Edinburgh: Edinburgh University Press, 1997.

GÜNTER, Klaus. Teoria da argumentação no direito e na moral: justificação e aplicação.

Tradução: Cláudio Molz. São Paulo: Landy Editora, 2004.

HART, H. L. A. O conceito de direito. Tradução: A. Ribeiro Mendes. Lisboa: Fundação Calouste Gulbenkian, [2007].

KELSEN, Hans. Teoria pura do direito. Tradução: João Baptista Machado. 6. ed. São Paulo: Martins Fontes, 1998.

MARANHÃO, Juliano Souza Albuquerque. Positivismo jurídico lógico-inclusivo. Madrid: Marcial Pons, 2012.

MACEDO JUNIOR, Ronaldo Porto. Do xadrez à cortesia: Dworkin e a teoria do direito contemporânea. São Paulo: Saraiva, 2013.

MIGUEL, Daniel Oitaven Pamponet. A tensão hermenêutica entre os papéis representativos do legislativo e do judiciário: uma interpretação construtiva do princípio da separação de poderes. 2012. Dissertação (Mestrado em Direito Público) - Faculdade de Direito, Universidade Federal da Bahia, Salvador, 2012.

NETO, Alfredo Copetti; ZANETI JR, Hermes. Os deveres de coerência e integridade: a mesma face da medalha? A convergência de conteúdo entre Dworkin e Maccormick na Teoria dos Precedentes Judiciais Normativos Formalmente Vinculantes. Derecho y Cambio Social, v. 46, p. 1-21, 2016.

NUNES, Dierle; PATRUS, Rafael Dilly. O IRDR do novo CPC: este "estranho" que merece ser compreendido. Revista Justificando, v. 6, 2015.

OLIVEIRA, Vallisney de Souza. O Incidente de resolução de demandas repetitivas introduzido no direito brasileiro pelo novo Código de processo civil. Revista de informação legislativa: RIL, v. 53, n. 210, p. 63-80, abr./jun. 2016. Disponível em: https://www12.senado.leg.br/ril/edicoes/53/210/ril_v53_n210_p63. Acesso em: 03/09/2020

ORUNESU, Claudina. Positivismo jurídico y sistemas constitucionales. Editora Marcial Pons. Madrid, 2012.

POGREBINSCHI, Thamy. Dworkin e o pragmatismo jurídico, ago. 2012.

SOPER, E. Philip. Legal theory and the obligation of a judge: The Hart/Dworkin dispute.

Michigan Law Review, v. 75, n. 3, p. 473-519, 1977. 


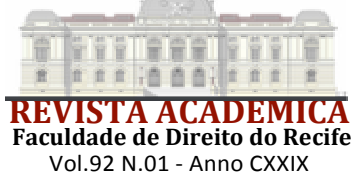

STRECK, Lenio Luiz. Dicionário de Hermenêutica: quarenta temas fundamentais da Teoria do Direito à luz da Crítica Hermenêutica do Direito. Belo Horizonte: Letramento, 2017.

STRECK, Lenio Luiz. Novo CPC terá mecanismos para combater decisionismos e arbitrariedades. Revista Consultor Jurídico, v. 18, p. 7, 2014.

STRECK, Lenio Luiz. O novo Código de Processo Civil (CPC) e as inovações hermenêuticas O fim do livre convencimento e a adoção do integracionismo dworkiniano. Revista de informação legislativa, v. 52, n. 206, p. 33-51, 2015.

STRECK, Lenio Luiz. Por que agora dá para apostar no projeto do novo CPC. Revista Consultor Jurídico, v. 21, p. 2, 2013.

STRECK, Lenio Luiz; MOTTA, Francisco José Borges. Relendo o debate entre Hart e Dworkin: uma crítica aos positivismos interpretativos. Revista Brasileira de Direito, v. 14, n. 1, p. 54-87, 2018. Disponível em: https://seer.imed.edu.br/index.php/revistadedireito/article/view/2451. Acessado em: 05 jun. 2020.

STRUCHINER, Noel. Uma análise da textura aberta da linguagem e sua aplicação ao Direito. Revista CEJ, 2002.

WALUCHOW, Wilfrid. Positivismo juridico incluyente. Madrid: Marcial Pons, 2007.

WAMBIER, Teresa Arruda Alvim; DIDIER JR., Fredie; TALAMINI, Eduardo; DANTAS, Bruno. Breves comentários ao Novo Código de Processo Civil. São Paulo: Revista dos Tribunais, 2015. 